\title{
PERCEPÇÃO DOS SERVIÇOS ECOSSISTÊMICOS DE ÁREAS VERDES URBANAS DE CURITIBA/PR
}

\author{
PERCEPTION OF ECOSYSTEM SERVICES ON URBAN GREEN AREAS IN CURITIBA/PR
}

\author{
Alessandro Panasolo ${ }^{1}$, Franklin Galvão ${ }^{2}$, Hermes Yukio Higachi ${ }^{3}$, \\ Edilson Batista de Oliveira ${ }^{4}$, Fernando Campos $^{5}$, Carlos Augusto Wroblewski ${ }^{6}$ \\ 1,2 Universidade Federal do Paraná, Curitiba, Paraná, Brasil-apanasolo@ufpr.br \&fgalvao@ufpr.br \\ ${ }_{3}^{3}$ Universidade Estadual de Ponta Grossa, Ponta Grossa, Paraná, Brasil - hhigachi@uepg.br \\ ${ }^{4}$ Embrapa Florestas, Curitiba, Paraná, Brasil-edilson.oliveira@embrapa.br \\ ${ }^{5,6}$ Fundação Grupo Boticário de Proteção à Natureza, Curitiba, Paraná, Brasil -fercampos@gmail.com \\ \& carloswroblewski@gmail.com
}

\section{RESUMO}

\begin{abstract}
O presente artigo tem como objetivo a identificação dos serviços ecossistêmicos (SE) de áreas verdes urbanas de Curitiba, PR. Utilizando um método exploratório, realizou-se uma pesquisa qualitativa com especialistas em meio ambiente, através da ferramenta Ecosystem Services Review - ESR, com o objetivo de identificar os SE mais importantes no que concerne à geração de bem-estar socioeconômico. Os locais de estudo são representativos dos principais contextos geográficos e fitofisionômicos da cidade, que juntos acumulam um total de 40 hectares protegidos, abrangendo um fragmento de Floresta Ombrófila Mista, bem como os últimos remanescentes de Campos Úmidos e Campos Secos de Curitiba. Conclui-se que os serviços ecossistêmicos estudados, especialmente aqueles apontados como mais relevantes, devem ser criteriosamente observados e incorporados na gestão das áreas verdes urbanas. Além disso, foi possível identificar quais os SE são considerados como não sendo passíveis de substituição, no caso de supressão das áreas verdes.
\end{abstract}

PALAVRAS-CHAVE: Floresta Urbana, Remanescentes Florestais Urbanos, Remanescentes Campestres Urbanos, Valor de Regulação, Valor Cultural.

\section{ABSTRACT}

This article aims to identify the ecosystem services (SE) of urban green areas of Curitiba, PR. Using an exploratory method, a qualitative research was carried out with specialists in the environment through the Ecosystem Services Review - ESR tool, in order to identify the most important SEs related to the generation of socioeconomic well-being. The study sites are representative of the main geographic and phytophysiognomic contexts of the city, which together accumulate a total of 40 protected hectares, encompassing a fragment of Mixed Ombrophilous Forest, as well as the last remnants of Fields and Dry Fields Mills of Curitiba. It is possible to conclude that the ecosystem services studied, especially those identified as more relevant, should be carefully observed and incorporated into the management of urban green areas. In addition, it was possible to identify which SEs are considered irreplaceable, in the case of suppression of green areas.

KEYWORDS: Urban Forest, Urban Forest Remnants, Urban Fields Remnants, Regulatory Value, Cultural Value. 


\section{INTRODUÇÃO}

Mais de $50 \%$ da população mundial vive em centros urbanos. Até o ano de 2050, projeta-se que esse valor chegue a $66 \%$, o que representaria aproximadamente 6 bilhões de pessoas (ONU, 2014). No país, a estimativa de habitantes para as cidades para o ano de 2020 é de cerca de 196,90 milhões, ou seja, 89,5\% da população atual (UNHABITAT, 2018). Contudo, áreas urbanas correspondem a apenas 2,4\% da superfície terrestre do planeta (MEA, 2005; MEXIA et al., 2018), o que sugere uma grande concentração de pessoas em pequenos espaços do território.

Projeções recentes da ONU indicam que no ano de 2030 haverá aproximadamente 41 megacidades com população maior do que 10 milhões de habitantes, o que levará à consequente pressão sobre os serviços ecossistêmicos nessas regiões. O mesmo estudo indica que o maior crescimento se dará nas cidades médias, o que reforça a importância de políticas públicas para garantir a provisão de serviços ecossistêmicos, tanto nas megacidades, como nas cidades de médio porte. Ressaltase, nesse contexto de crescimento urbano, a relevância das 41 maiores cidades do mundo por carregarem um alto poder de mudança no cenário global, tornando-se corresponsáveis no combate aos grandes desafios ambientais e sociais da humanidade, principalmente pela importância econômica que terão (ONU, 2014).

O aumento populacional e a elevada expansão urbana, muitas vezes desordenada, têm produzido efeitos adversos nos serviços ecossistêmicos (SE), causando a perda da biodiversidade e prejudicando a provisão dos serviços ecossistêmicos, impactando direta e indiretamente o bemestar humano (JOLY et al., 2017).

As áreas urbanas têm uma taxa de crescimento populacional mais rápida do que qualquer outro tipo de uso da terra tornando-se a principal consumidora dos serviços ecossistêmicos (SIEBER et al., 2015).

A dependência direta ou indireta dos serviços ecossistêmicos para o bem-estar humano, tais como alimentos, água, controle de doenças, regulação do clima, realização espiritual e prazer estético, já é reconhecida há muitos anos (MEA, 2005; NAHLIK, et al., 2012). O tema ganhou dimensão no campo da valoração econômica com o trabalho de Costanza et al. (1997) que abordaram o valor de 17 serviços ecossistêmicos para 16 biomas, ressaltando a importância do funcionamento do sistema de suporte à vida na Terra.

Igualmente, a avaliação das relações de impacto e de dependência entre negócios, biodiversidade e serviços ecossistêmicos nos processos produtivos foi incorporada pelo setor empresarial (HANSON et al., 2012; CEBDS, 2013) e pela Convenção da Diversidade Biológica (CBD), ressaltando os benefícios econômicos da biodiversidade, os custos da perda de biodiversidade e a deficiência em se adotarem medidas de proteção versus o custo efetivo de conservação (TEEB, 2010).

O termo Serviços Ecossistêmicos (ES) refere-se aos "benefícios que as pessoas obtêm dos ecossistemas". De acordo com a Avaliação Ecossistêmica do Milênio (MEA, 2005), são quatros os tipos de serviços ecossistêmicos que beneficiam as populações humanas: Serviços de Provisionamento (alimentos, água, lenha, fibras, princípios ativos e recursos genéticos); Serviços de Suporte (formação de solos, produção primária, ciclagem de nutrientes e processos ecológicos); Serviços Culturais (espiritualidade, lazer, inspiração, educação e simbolismos); e, Suporte de Regulação (regulação do clima, controle de doenças, controle de enchentes e desastres naturais, purificação da água, purificação do ar e controle de erosão).

Diante desse cenário, Rockström (2015) afirma que alguns dos maiores desafios para o planejamento urbano no século XXI são a identificação e a gestão dos serviços ecossistêmicos em áreas urbanas. A literatura internacional, especialmente os trabalhos de Breuste e Artmann (2015) e Chan et al. (2016), demonstra a importância das áreas verdes urbanas não só para os serviços ecossistêmicos ligados à biodiversidade, mas também no que se refere aos valores emocionais, psíquicos, relacionais e de envolvimento entre as pessoas de um determinado local em que a área verde se encontra.

Outro fator a ser levado em consideração é a capacidade que ambientes naturais possuem de colaborar com a saúde mental das pessoas. Assim, ao se considerar as áreas verdes como prioridade para políticas de desenvolvimento, priorizar-se-á a geração de benefícios como redução do estresse e dos níveis de ansiedade das pessoas, o que é de grande valia em um mundo com mais de 450 milhões com algum tipo de transtorno psíquico (CAMPBELL et al., 2012).

Assim, além dos benefícios ao bem-estar humano em geral, destaca-se a importância ecológica das áreas verdes localizadas em ambiente urbano, especialmente como habitat para espécies. A conservação dos ecossistemas nativos em áreas urbanas é essencial, também, por estarem as grandes cidades situadas em hotspots de biodiversidade.

Diante desse contexto, o presente estudo teve como objetivos principais avaliar qualitativamente os serviços 
ecossistêmicos prestados por três áreas verdes urbanas na região de Curitiba/PR, verificar quais desses serviços são mais relevantes na geração de bem-estar socioeconômico, de modo a responder três questões: (i) Quais são, hierarquicamente, os serviços ecossistêmicos mais importantes fornecidos pelas áreas verdes urbanas para geração de bem-estar socioeconômico no município de Curitiba? (ii) Os serviços ecossistêmicos das áreas verdes estudadas são importantes para o estabelecimento de estratégias de conservação e de gestão urbana? (iii) No caso da supressão das áreas verdes urbanas, seria possível substituir os serviços ecossistêmicos fornecidos por elas através da adoção e/ou implementação de estratégias, projetos e/ou produtos que apresentasse os mesmos benefícios?

\section{MATERIAL E MÉTODOS}

\section{Área de estudo}

A área de estudo foi a cidade de Curitiba, capital do estado do Paraná, localizada na região Sul do Brasil, entre $25^{\circ} 20^{\prime}$ e $25^{\circ} 38^{\prime}$ de latitude S e $49^{\circ} 11^{\prime}$ e $40^{\circ} 23^{\prime}$ de longitude W, com uma área de $432,17 \mathrm{~km}^{2}$ e altitude média de 934 m s.n.m., variando de 1021 a 865 m s.n.m. (IPPUC, 2014). Destaca-se que a referida área de estudo incluiu uma pequena porção do munícipio de Araucária. Para fins metodológicos do presente artigo, entende-se que os serviços ecossistêmicos fornecidos pela área localizada na divisa dos municípios prestam maior contribuição à Curitiba.

Situada no primeiro planalto paranaense, Curitiba possui 75 bairros e é considerada $100 \%$ urbana. A população é de 1.751 .907 habitantes, o que representa $54,3 \%$ da população da Região Metropolitana de Curitiba, que é composta por 29 municípios, configurando como a oitava região metropolitana mais populosa do Brasil, com 3.502.790 habitantes (população estimada em 2015 pelo IBGE), e nela concentra $31,37 \%$ da população total do Estado (PARANÁ, 2012; COMEC, 2017).

Segundo a classificação de Köppen, situa-se no contexto climático $\mathrm{Cfb}$, que é um clima mesotérmico, úmido e superúmido, sem estação seca, com verões frescos e invernos com geadas frequentes e com ocorrências ocasionais de neve (ALVAREZ et al, 2014).

O município de Curitiba está inserido no Bioma Mata Atlântica, na ecorregião da floresta com araucária (Floresta
Ombrófila Mista) e dos campos (Estepe).

Curitiba, conforme mapeamento feito pela Secretaria Municipal de Meio Ambiente, possui áreas com floresta em bom estado de conservação, representando cerca de 780.000 ha ou $18 \%$ do município. Deste total, cerca de $75 \%$ estão em propriedades particulares, localizadas principalmente nos bairros de Santa Felicidade, Umbará e Barreirinha, sendo que os outros $25 \%$ estão em áreas públicas (SPVS, 2017). A cobertura de vegetação cobre $43,69 \%$ da cidade, sendo $8,98 \%$ floresta urbana pública e $34,70 \%$ floresta urbana particular (GRISE et al., 2016).

Quanto aos campos, esses foram praticamente suprimidos, sendo encontrados de forma mais contínua apenas nos municípios do entorno. Em Curitiba, apenas poucos e pequenos remanescentes ainda podem ser observadas em terrenos baldios, raros fundos de vales ou quintais com solo descoberto (KERSTEN; GALVÃO, 2014).

As áreas escolhidas para a avaliação dos serviços ecossistêmicos situam-se em diferentes contextos geográficos e fitofisionômicos do município de Curitiba (Figura 1) e acumulam um total de 40 hectares protegidos. Abrange remanescentes de Estepe (campos) (Estação Ecológica Teresa Urban), de formações aluviais (Área Verde da REPAR) e montana (Reserva Particular do Patrimônio Natural Municipal [RPPNM] Airumã) da Floresta Ombrófila Mista (floresta com araucária), fisionomia mais frequentemente associada à região.

A Reserva Particular do Patrimônio Natural Municipal Airumã tem $28.500 \mathrm{~m}^{2}$ e está localizada no bairro São João (Regional Santa Felicidade), na porção norte/noroeste de Curitiba. Foi criada no ano de 2013, preservando um fragmento de Floresta Ombrófila Mista em estágio médio e avançado de sucessão (SOCIEDADE CHAUÁ; PROFLOR, 2013). O perfil sóciodemográfico do bairro é considerado de boa qualidade para viver. Possui infraestrutura boa de coleta de lixo, distribuição de energia elétrica e escoamento sanitário. Ainda, tem renda domiciliar mensal de $\mathrm{R} \$$ 5.139,76, acima da média do município, alto índice de área verde, perfazendo $540,53 \mathrm{~m}^{2}$ por habitante considerando a média geral do município que é de 58 $\mathrm{m}^{2} /$ habitante - densidade demográfica baixa, de 10,72 habitantes/ha ${ }^{1}$, e taxa de homicídios e ocorrências gerais ${ }^{2}$ de 0,00 por 100.000 habitantes (IPPUC, 2015c).

com base nas informações da Polícia Civil e no censo demográfico 2010 (IBGE).
Densidade demográfica da cidade de Curitiba: 40,30 hab/ha.

Considera-se ocorrências gerais os homicídios, suicídios, confronto com a polícia, latrocínio e lesão corporal sem morte. Índice calculado 


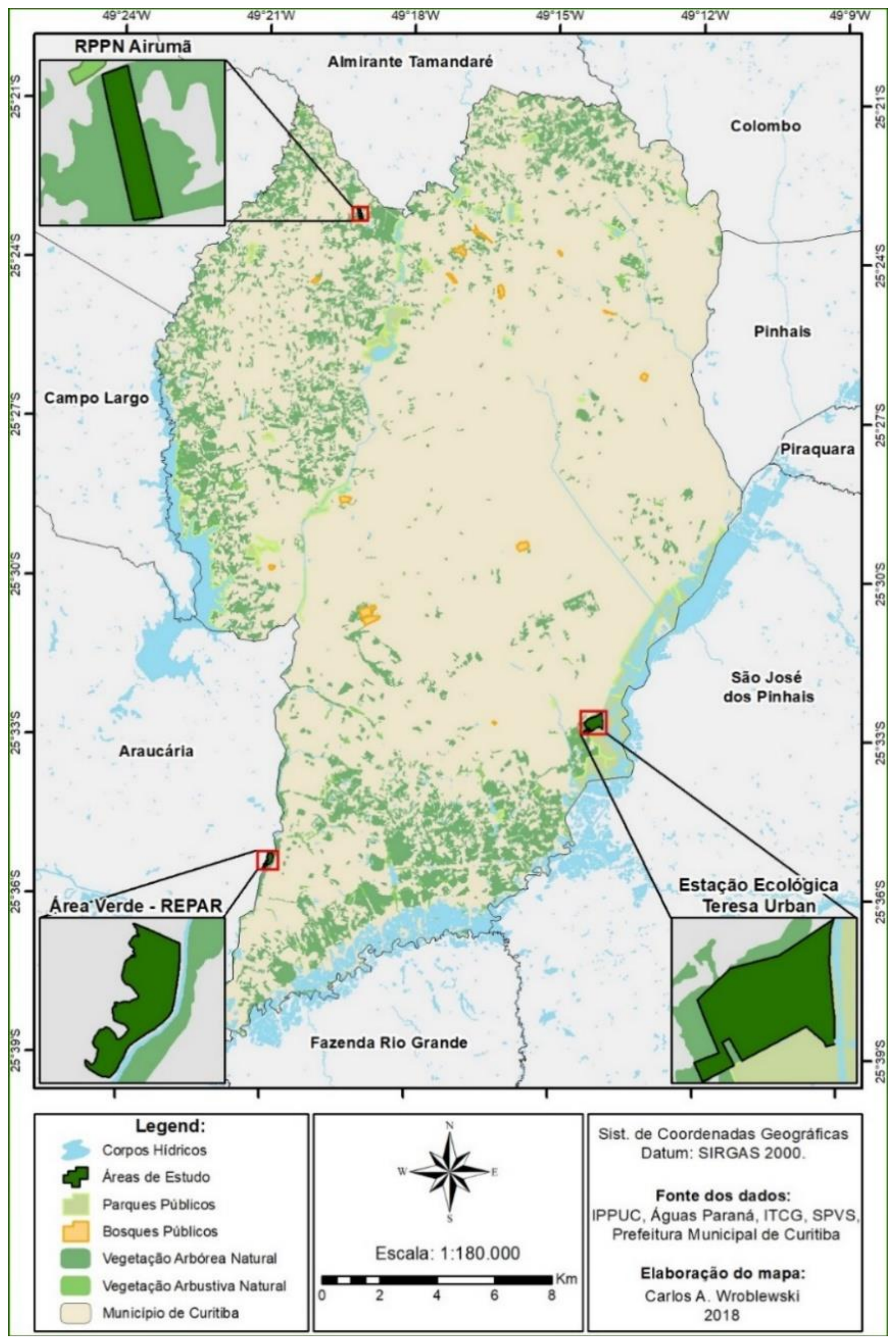

Figura 1. Mapa de vegetação remanescente do município de Curitiba com destaque a localização da RPPNM Airumã, da Estação Ecológica Teresa Urban e da área verde na Refinaria Presidente Getúlio Vargas - REPAR. 
A Estação Ecológica Teresa Urban é uma Unidade de Conservação pública municipal criada 2016, tendo a particularidade de ser a única do município a proteger a fitofisionomia de campos, que, no presente caso, estão associados à Floresta Ombrófila Mista Montana e Aluvial. A área possui $275.900 \mathrm{~m}^{2}$ e se encontra na porção sudeste do município, no bairro periférico Alto Boqueirão, próximo à divisa com o município de São José dos Pinhais. O perfil sociodemográfico do bairro revela que possui infraestrutura - coleta de lixo, distribuição de energia elétrica e escoamento sanitário - de boa qualidade, tem densidade demográfica alta, de 44,77 habitante/ha, altas taxas de homicídios, de 48,44, e de ocorrências gerais, de 55,90 , por 100.000 habitantes, sendo mais elevada que a média geral do município. Possui renda média domiciliar mensal de $\mathrm{R} \$ 2.370,95$ e índice de área verde de 27,42 $\mathrm{m}^{2}$ por habitante (IPPUC, 2015a).

A área verde da REPAR localiza-se na divisa dos munícipios de Araucária, bairro Tindiquera ${ }^{3}$, e de Curitiba, bairro Campo do Santana. A área possui $92,000 \mathrm{~m}^{2} \mathrm{e}$ pertencente à Refinaria Presidente Getúlio Vargas. As características vegetacionais incluem a presença de remanescentes da Floresta Ombrófila Mista Aluvial, em bom estado de conservação (BARDDAL et al., 2004).

O perfil sociodemográfico do bairro Campo do Santana indica ter infraestrutura - coleta de lixo, distribuição de energia elétrica e escoamento sanitário - de qualidade. Possui renda média domiciliar mensal de $\mathrm{R} \$ 1.713,44$, com densidade demográfica de 12,35 habitantes/ha e com índice de área verde por habitante de 255,27 $\mathrm{m}^{2}$. Apresenta taxa de homicídios e de ocorrências gerais de 15,01 por 100.000 habitantes (IPPUC, 2015b).

\section{Procedimento metodológico}

Considerando os objetivos, este estudo apresenta um caráter exploratório, que normalmente utiliza pesquisas com especialistas e revisão bibliográfica, dispensando um processo de amostragem rigoroso e quantitativo para coleta e análise dos dados (GIL, 2010).

Dessa maneira, uma abordagem de pesquisa qualitativa foi considerada a mais apropriada. O método de pesquisa utilizado foi 'entrevista com especialistas', uma vez que esse método é o mais indicado para estudos nos quais não há informações prévias ou essas estão incompletas (YIN, 2010; GIL, 2010).

Não foi apresentado o perfil sociodemográfico do bairro Tindiquera pelo fato de não possuir ocupação habitacional ao lado da área pesquisada.
A estratégia de amostragem aplicada foi uma combinação entre as técnicas intencional e por conveniência. Técnica de amostragem intencional significa que os participantes foram selecionados de acordo com critérios pré-definidos e particularmente relevantes para o objetivo da pesquisa. Tal técnica é não probabilística e requer considerável conhecimento da população e do grupo selecionado. Por sua vez, na técnica por conveniência, o pesquisador seleciona elementos dos quais ele tem acesso e admite que eles representam a população (GIL, 2010).

Para participar da pesquisa, foram selecionados especialistas nas áreas de meio ambiente, com foco em conservação da natureza e gestão sustentável dos recursos naturais e de planejamento urbano. Além disso, todos deveriam conhecer o contexto do município de Curitiba para que suas respostas pudessem refletir com maior assertividade a realidade local.

Das diversas ferramentas para mensuração e avaliação de serviços ecossistêmicos, a Ecosystem Services Review ESR, desenvolvida pelo World Resources Institute (WRI) e World Business Council for Sustainable Development (WBCSD), apresenta-se como um método estruturado de razoável acessibilidade e ampla aplicabilidade para que gestores de empresas desenvolvam estratégias para gestão de riscos e oportunidades que surgem das dependências e impactos das empresas nos ecossistemas. É uma ferramenta para desenvolvimento estratégico, não apenas avaliação ambiental (HANSON et al., 2012).

O ESR é uma ferramenta com aplicação focada em empresas, sendo que sua utilização por gestores públicos, possuindo como escopo os recortes geográficos das cidades, ainda é bastante limitada. Nesse sentido, já há alguns esforços para adaptar tal ferramenta para o ambiente urbano (SIEBER et al., 2015; PONS et al., 2016). Seguindo a lógica dessas recentes abordagens, este estudo realizou uma adaptação da ferramenta ESR para torná-la compatível e aplicável ao ambiente urbano.

O ESR padrão possui cinco fases: (i) seleção do escopo; (ii) identificação dos serviços ecossistêmicos prioritários; (iii) análise de tendências nos serviços prioritários; (iv) identificação de riscos e oportunidades; e (v) desenvolvimento de estratégias. No presente estudo, somente as duas primeiras foram objetos de abordagem. A fase de seleção do escopo se refere à definição dos limites dentro dos quais será conduzida a ESR. Neste estudo, foi considerada a influência de impactos ou relação de 
dependência que as três áreas verdes urbanas exercem no município de Curitiba.

$\mathrm{Na}$ fase de identificação dos serviços ecossistêmicos prioritários foi avaliada sistematicamente a relevância e o fornecimento dos serviços ecossistêmicos para as comunidades inseridas no escopo em mais de vinte serviços ecossistêmicos. Foram determinados quais são os serviços prioritários, isto é, os mais relevantes para o bemestar das populações. Essa etapa é crucial, pois, nela se analisou o impacto que as áreas selecionadas exercem ao fornecerem determinados serviços ecossistêmicos e, dessa forma, permitiu-se estabelecer uma relação de dependência da sociedade com as áreas verdes urbanas, uma vez que são elas as responsáveis pelo fornecimento desses serviços.

Para evidenciar ainda mais essa relação de dependência e, portanto, o caráter de prioridade do serviço ecossistêmico fornecido pelas áreas verdes urbanas, avaliou-se a possibilidade de substituição dos serviços ecossistêmicos fornecidos por estas áreas caso suprimidas, através da adoção e/ou implementação de estratégias, projetos e/ou produtos que apresentasse a mesma relação custo-efetividade ${ }^{4}$.

Foram selecionados 115 especialistas nas áreas de meio ambiente. Deste modo, para cada um deles foi enviado um questionário via plataforma Google Forms (Tabela 1), com perguntas relacionadas à contribuição das três áreas verdes estudadas na quantidade e qualidade dos serviços ecossistêmicos prestados, além de perguntas relacionadas à provisão de serviços ecossistêmicos fornecidos por todas as áreas verdes presentes na região de Curitiba.

As respostas obtidas foram de especialistas que representam organizações de pesquisa, organizações não governamentais ambientalistas e poder público local, tais como Embrapa, Organização das Nações Unidas para a Alimentação e a Agricultura (FAO), Fundação Grupo Boticário de Proteção à Natureza, SOS Mata Atlântica, Instituto Nacional de Pesquisas Espaciais, União Internacional para a Conservação da Natureza (IUCN), Secretaria de Desenvolvimento Sustentável de Santa Catarina, Secretaria Municipal de Meio Ambiente de São José dos Pinhais, Fundação Neotrópica, Sociedade de Pesquisa em Vida Selvagem e Educação Ambiental, Secretaria Estadual de Meio Ambiente do Paraná e Universidade Tecnológica Federal do Paraná.
Tabela 1. Perguntas do questionário enviado aos especialistas sobre os serviços ecossistêmicos prestados pelas três áreas verdes estudadas.

1) Selecione os 5 (cinco) serviços ecossistêmicos mais importantes fornecidos pelas áreas verdes urbanas para geração de bem-estar socioeconômico no município de Curitiba

2) A Reserva Particular do Patrimônio Natural Airumã, contribui para o fornecimento em quantidade e/ou qualidade de quais serviços ecossistêmicos listados abaixo?".

3) A Estação Ecológica Teresa Urban, contribui para o fornecimento em quantidade e/ou qualidade dos serviços ecossistêmicos listados abaixo?

4) A área verde da REPAR, contribui para o fornecimento em quantidade e/ou qualidade dos serviços ecossistêmicos listados abaixo?

5) No caso da supressão das áreas verdes urbanas, quais serviços ecossistêmicos por elas fornecidos não seriam possíveis de serem substituídos por adoção e/ou implementação de estratégias, projetos e/ou produtos que apresentasse os mesmos benefícios?

\section{RESULTADOS}

Os resultados demonstram que $100 \%$ dos entrevistados consideram a regulação do clima local como sendo o serviço ecossistêmico mais importante prestado pelas áreas verdes em Curitiba (Figura 2). Do mesmo modo, destaca-se, também, a relevância das áreas verdes para a manutenção da qualidade do ar, condição essa que foi apontada por $70 \%$ dos entrevistados.

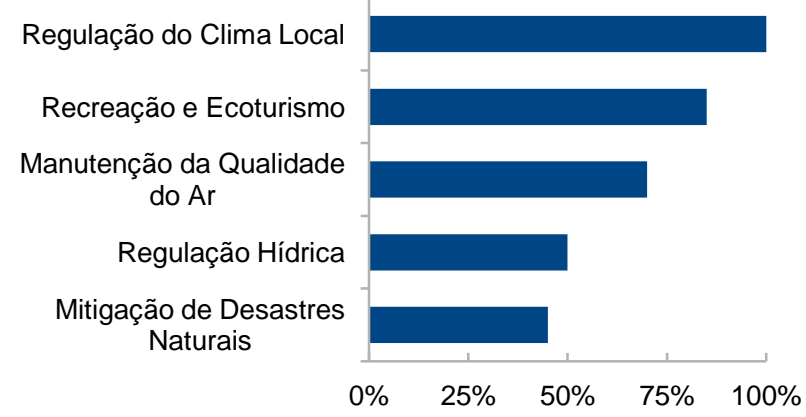

Figura 2. Resposta para a pergunta: "Selecione os 5 (cinco) serviços ecossistêmicos mais importantes fornecidos pelas áreas verdes urbanas para geração de bem-estar socioeconômico no município de Curitiba".

Além dos já citados, os serviços de regulação hídrica e de mitigação de desastres naturais também apareceram

se, portanto, de identificar e medir os custos e benefícios das diversas alternativas, para compará-las entre si e escolher a mais vantajosa do ponto de vista da relação entre benefício e custo. 
entre os cinco serviços ecossistêmicos mais citados por especialistas.

Afora dos serviços de regulação, $85 \%$ dos entrevistados consideram de grande importância o serviço de recreação e turismo provido pelas áreas verdes do município, demonstrando também que serviços ecossistêmicos culturais.

Após a identificação dos serviços ecossistêmicos mais relevantes para a cidade como um todo, buscou-se avaliar quais são os serviços ecossistêmicos mais importantes fornecidos por cada uma das três áreas verdes selecionadas na percepção dos especialistas.

Deste modo, a Reserva Particular do Patrimônio Natural Airumã se destacou na regulação do clima local 75\% (Figura 3), e manutenção da qualidade do ar 70\%, ratificando o panorama vislumbrado para o município geral.

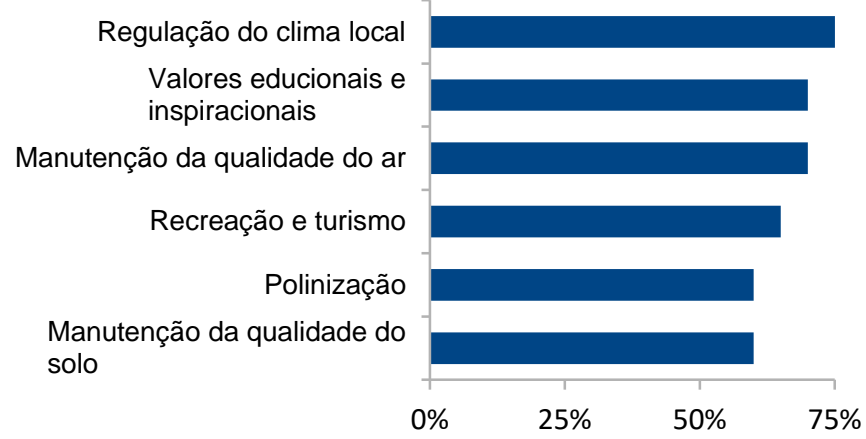

Figura 3. Resposta para a pergunta: “A Reserva Particular do Patrimônio Natural Airumã, contribui para o fornecimento em quantidade e/ou qualidade de quais serviços ecossistêmicos listados abaixo?".

No que concerne aos outros serviços ecossistêmicos citados, para $70 \%$ dos entrevistados a área é significativa para a promoção de valores educacionais e inspiracionais, percepção que reflete os esforços das ações de educação ambiental constantemente promovidas pelos mantenedores da área em questão.

Por fim, os entrevistados também elencaram como serviços ecossistêmicos indispensáveis, as questões da polinização e a manutenção da qualidade do solo promovida pela RPPNM Airumã.

No que se refere à Estação Ecológica Teresa Urban, do mesmo modo que a RPPNM Airumã, teve grande destaque na regulação do clima local para $85 \%$ dos entrevistados (Figura 4), fato que se explica, pois a área faz parte de um dos últimos remanescentes de vegetação no bairro Alto Boqueirão.

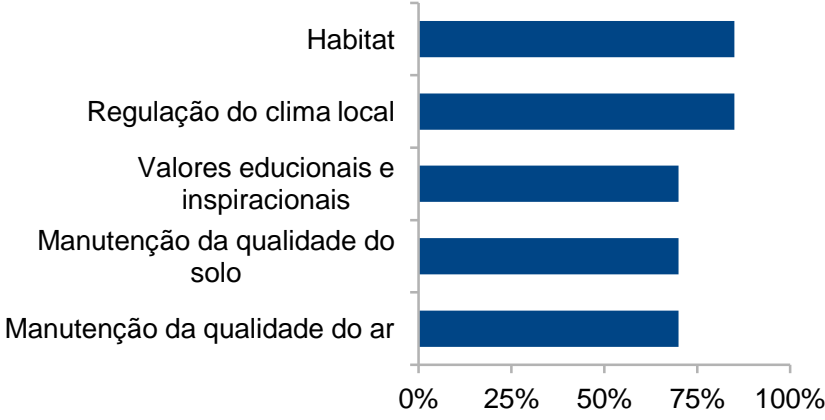

Figura 4. Resposta para a pergunta: "A Estação Ecológica Teresa Urban, contribui para o fornecimento em quantidade e/ou qualidade dos serviços ecossistêmicos listados abaixo?".

Destacou-se, também, para $85 \%$ dos entrevistados, como provedora de habitat para espécies. Ademais, para 70\% dos entrevistados, a Estação Ecológica Teresa Urban é essencial quando se leva em consideração os serviços ecossistêmicos de manutenção da qualidade do ar e a manutenção da qualidade do solo. Por fim, os especialistas também citam a área como sendo provedora de valores educacionais e inspiracionais.

Com relação à área verde da REPAR, 65\% dos entrevistados atestam sua influência para a regulação do clima local, a exemplo das outras áreas (Figura 5). Do mesmo modo que na Estação Ecológica Teresa Urban, destacam os serviços de polinização na região providos pela área verde, bem como a manutenção da qualidade do ar que demonstrou ser dos cinco serviços ecossistêmicos mais significativos prestados pela área. Diferentemente das outras áreas pesquisadas, os especialistas apontaram a ciclagem de nutriente e a ciclagem hídrica como dois dos cinco mais importantes serviços ecossistêmicos mais importantes prestados pela área em estudo.

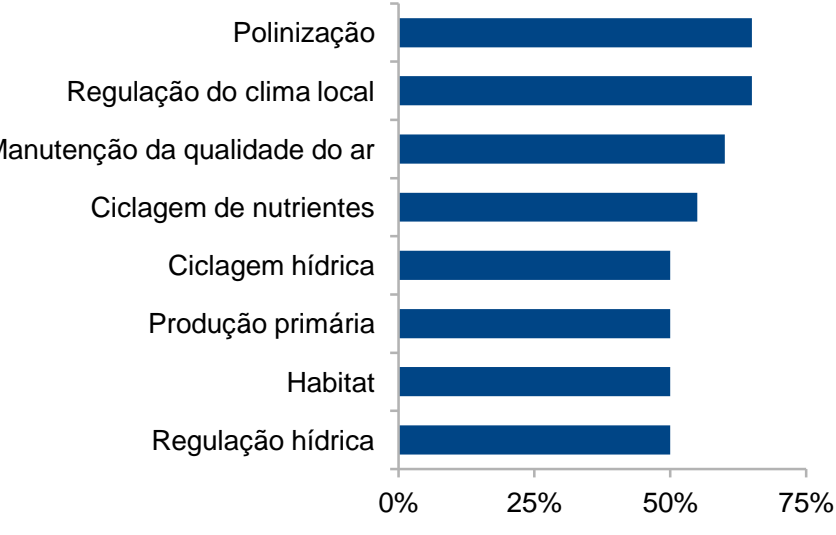

Figura 5. Resposta para a pergunta: “A área verde da REPAR, contribui para o fornecimento em quantidade e/ou qualidade dos serviços ecossistêmicos listados abaixo?". 
Para evidenciar a relação de dependência e, portanto, o caráter de prioridade do serviço ecossistêmico fornecido pelas áreas verdes urbanas, foi avaliada a possibilidade de substituição dos serviços ecossistêmicos por elas fornecidos através da adoção e/ou implementação de estratégias, projetos e/ou produtos que apresentasse a mesma relação custo-efetividade, em caso de supressão dessas áreas.

Assim, para essa suposição, 75\% dos entrevistados avaliam que não seria possível a substituição da regulação do clima local que as áreas verdes promovem por outro projeto ou produto que apresentasse o mesmo benefício (Figura 6). Destaca-se, também, que para $70 \%$ dos entrevistados os valores éticos e espirituais das áreas verdes urbanas, bem como os serviços de habitat para espécies, não poderiam ser substituídos por algum produto ou serviço.

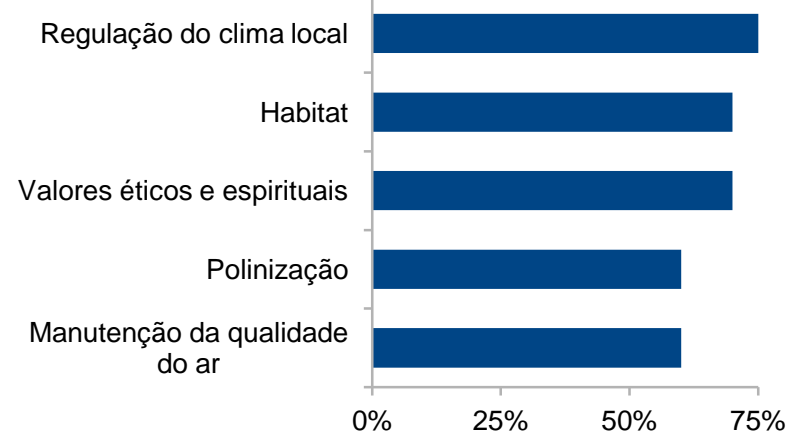

Figura 6. Resposta para a pergunta: "No caso da supressão das áreas verdes urbanas, quais serviços ecossistêmicos por elas fornecidos não seriam possíveis de serem substituídos por adoção e/ou implementação de estratégias, projetos e/ou produtos que apresentasse os mesmos benefícios?".

Destaca-se, também, que $60 \%$ dos entrevistados consideraram impossível a substituição dos serviços de polinização, manutenção da qualidade do ar e recursos genéticos com uma melhor relação custo-efetividade.

\section{DISCUSSÃO}

Diante dos resultados, verifica-se que para as três áreas verdes abrangidas no estudo a regulação do clima local e a manutenção da qualidade do ar são os serviços ecossistêmicos mais relevantes, ficando sempre entre os cinco mais citados. Além disso, as percepções dos especialistas para cada área verde vêm ao encontro dos dados obtidos para o ambiente urbano de Curitiba, de forma geral, onde serviços de regulação são os mais citados.

Ainda, sobre os cinco serviços ecossistêmicos mais importantes fornecidos pelas áreas verdes na cidade de Curitiba, restou demonstrado que os serviços recreativos contribuem para a qualidade de vida, saúde física e espiritual e para a conexão social, sendo imprescindíveis para o bem-estar, reduzindo o stress e influenciando positivamente o humor das pessoas (ABKAR et al., 2010; TAMEKO et al., 2011). Assim, conhecer, vivenciar a natureza e caracterizar nossas conexões intangíveis com esses ambientes naturais ajudam a moldar decisões que beneficiam as pessoas e os ecossistemas dos quais dependemos (BALMFORD et al., 2009; RUSSELL et al., 2013).

Diversos estudos demonstram que a degradação da biodiversidade e dos serviços ecossistêmicos (BSE) vem causando surtos de doenças, riscos para a segurança alimentar, hídrica e climática, desastres naturais e marginalização de populações humanas (ABC, 2017).

Ainda, é preciso sublinhar que os resultados obtidos na RPPNM Airumã, sobre regulação do clima local (LEAL et al., 2014) e manutenção da qualidade do ar, revela-se de grande importância (LEUNG et al., 2011), pois a referida a área está localizada em um bairro predominantemente residencial, com forte expansão urbana da cidade de Curitiba que, por consequência, está diminuindo em grande medida as áreas verdes restantes na região.

No que tange ao grau de essencialidade da polinização e manutenção da qualidade do solo da RPPNM Airumã relatado pelos especialistas, deve-se a qualidade do maciço florestal presente na unidade que, além de promover o fluxo de pássaros e de insetos polinizadores, também colabora para que o solo fique protegido e mantenha as suas características e contribui para o estoque de carbono (CARVALHO et al., 2010).

Os resultados, em outra linha, evidenciaram que a Estação Ecológica Teresa Urban deve ser considerada como uma ilha de frescor em meio a profusão de concreto. Esta avaliação é bastante compreensível, pois até há pouco tempo esse enclave de campo nativo remanescente de Curitiba permanecia em total desconhecimento, o que reforça a ideia do potencial da área como sendo um rico habitat para espécies de fauna e flora.

O grau de relevância da Estação Teresa Urban para a manutenção da qualidade do ar e do solo apontada pelos especialistas entrevistados surpreendeu, já que a área não possui nenhuma estrutura para receber visitantes e encontra-se em situação de descaso e com sinais de degradação. Por outro lado, reflete o potencial que essa 
área possui para educar e inspirar a sociedade caso fossem implementadas políticas públicas adequadas voltadas para a gestão sustentável dessa área.

De modo análogo ao que ocorre na Estação Ecológica Teresa Urban, a área verde da REPAR destaca-se pela sua importância no que tange os serviços ecossistêmicos de polinização e regulação climática. Tal fato deve-se ao enclave de vegetação em que a área se encontra, pois os seus arredores são dominados pela área urbana e por uma considerável zona industrial pesada. Assim sendo, a área provê fluxo de animais polinizadores, ao mesmo tempo que colabora para a geração de zonas de frescor no local em que se encontra, o que corrobora o terceiro serviço ecossistêmico mais citado para a área, o de qualidade do ar (NOWAK et al., 2013).

Outrossim, valores educacionais e inspiracionais foram serviços ecossistêmicos identificados em duas áreas (Figuras 4 e 5), demonstrando também a importância dos valores culturais das áreas verdes urbanas.

Os serviços ecossistêmicos habitat (suporte), recreação e turismo (cultural) e ciclagem de nutrientes (regulação) foram elencados de modo exclusivo para cada uma das três áreas verdes. Tais serviços têm grande relevância no ambiente urbano, fato corroborado pelo trabalho de Langemeyer et al. (2015), na cidade de Barcelona.

Por fim, importa destacar da análise dos resultados elencados no gráfico (Figura 6) que todos os serviços ecossistêmicos apontados como insubstituíveis aparecem em pelo menos duas das três áreas estudadas. A qualidade do ar e a regulação do clima aparecem entre os cinco principais serviços ecossistêmicos de todas as áreas analisadas. O habitat, a polinização e os valores educacionais e inspiracionais foram elencados dentre os cinco principais serviços ecossistêmicos de duas áreas estudadas. Nesse sentido, tais resultados corroboram a percepção da importância que as áreas pesquisadas representam para o município de Curitiba.

\section{CONCLUSÕES}

As análises realizadas permitem concluir que:

- Os serviços mais importantes fornecidos pelas áreas verdes urbanas para geração de bem-estar socioeconômico no município de Curitiba são: a) regulação do clima local; b) Recreação e Ecoturismo; c) Manutenção da qualidade do ar; d) Regulação hídrica e; e) Mitigação de desastres naturais.

- Torna-se evidente que os serviços ecossistêmicos citados, especialmente aqueles apontados como mais relevantes, devem ser criteriosamente observados e incorporados na gestão da conservação urbana, uma vez que são interpretados por especialistas de diversas áreas como sendo indispensáveis no contexto das megacidades e das médias cidades.

- Os serviços ecossistêmicos apontados como sendo não passíveis de substituição, no caso de supressão das áreas verdes, são igualmente apontados, por mais de uma vez, como sendo relevantes nas áreas objeto de pesquisa.

- As percepções quanto a relevância e indispensabilidade dos SE são cruciais para o estabelecimento de estratégias de conservação e de gestão das áreas verdes urbanas. Pois, na hipótese de degradação das referidas áreas, que as tornassem incapazes de fornecer os serviços ecossistêmicos, não seria possível substituí-los pela adoção e/ou implementação de outras estratégias, projetos e/ou produtos com melhor relação custo-efetividade. Portanto, tais serviços identificados devem ser foco das políticas de conservação e de gestão sustentável dos recursos naturais.

\section{REFERÊNCIAS}

ABC - Academia Brasileira de Ciências. Biodiversidade, ecossistemas e serviços ecossistêmicos. Rio de Janeiro, 2017. Disponivel em: http://www.abc.org.br/?-BiodiversidadeEcossistemas-e-Servicos-Ecossistemicos

ABKAR, M. et al. The role of urban green spaces in mood change. Australian Journal of Basic \& Applied Sciences, v.4, n.10, p.53525361, 2010.

ALVARES, C.A. et al. Köppen's climate classification map for Brazil. Meteorologische Zeitschrift, v.22, n.6, p.711-728, 2014.

BALMFORD, A. et al. A global perspective on trends in naturebased tourism. PLoS Biology, v.7, e1000144, 2009.

BARDDAL, M.L. et al. Caracterização florística e fitossociológica de um trecho sazonalmente inundável de Floresta Aluvial, em Araucária, PR. Ciência Florestal, v.14, n.2, p.37-50, 2004.

BREUSTE, J.H.; ARTMANN, M. Allotment gardens contribute to urban ecosystem service: case study Salzburg, Austria. Journal of Urban Planning and Development, v.141, n.3, p.A5014005, 2015.

CAMPBELL, K. et al. Panorama da biodiversidade nas cidades ações e políticas: avaliação global das conexões entre urbanização, biodiversidade e serviços ecossistêmicos. Montreal: Secretariat of the Convention on Biological Diversity, 2012.

CARVALHO, J.I.N. et al. Potencial de sequestro de carbono em diferentes biomas do Brasil. Revista Brasileira de Ciência do Solo, v.34, p.277-289, 2010.

CEBDS - Conselho Empresarial Brasileiro para o Desenvolvimento Sustentável. Biodiversidade e serviços ecossistêmicos: a experiência das empresas brasileiras. Rio de Janeiro, 2013. Disponível em: http://cebds.org/wp-content/uploads/2014/02/ 
Biodiversidade-e-servi\%C3\%A7os-ecossist\%C3\%AAmicos_2012.p t_.pdf

CHAN, K.M.A. et al. Opinion: why protect nature? Rethinking values and the environment. Proceedings of the National Academy of Sciences, v.113, n.6, p.1462-1465, 2016.

COMEC - Coordenação da Região Metropolitana de Curitiba. Região metropolitana de Curitiba. Curitiba, 2017. Disponível em: http://www.comec.pr.gov.br/modules/conteudo/conteudo.php ?conteudo $=123$

COSTANZA, R. et al. The value of the world's ecosystem services and natural capital. Nature, v.387, p.253-260, 1997.

GIL, A.C. Como elaborar projetos de pesquisa. 5.ed. São Paulo: Atlas, 2010.

GRISE, M.M. et al. A floresta urbana da cidade de Curitiba-PR. Floresta, v.46, n.4, p.425-438, 2016.

HANSON, C. et al. The corporate ecosystem services review: guidelines for identifying business risks and opportunities arising from ecosystem change. Washington: World Resources Institute, 2012. Disponível em: https://www.issuelab.org/resour ce/guidelines-for-identifying-business-risks-and-opportunities-ar ising-from-ecosystem-change.html

IPPUC - Instituto de Pesquisa e Planejamento Urbano de Curitiba. Curitiba em dados. Curitiba, 2014. Disponível em: http://curitibaemdados.ippuc. org.br/

IPPUC - Instituto de Pesquisa e Planejamento Urbano de Curitiba. Nosso bairro: Boqueirão. Curitiba: IPPUC, 2015a. Disponível em: http://www.ippuc.org.br/nossobairro/anexos/56-Boqueir\%C3\% A3o.pdf

IPPUC - Instituto de Pesquisa e Planejamento Urbano de Curitiba. Nosso bairro: Campo de Santana. Curitiba: IPPUC, 2015b. Disponível em: http://www.ippuc.org.br/nossobairro/anexos/ 71-Campo\%20do\%20Santana.pdf

IPPUC - Instituto de Pesquisa e Planejamento Urbano de Curitiba. Nosso bairro: São João. Curitiba: IPPUC, 2015c. Disponível em: http://www.ippuc.org.br/nossobairro/anexos/48-S\%C3\%A3०\%2 0J०\%C3\%A3o.pdf

JOLY, C.A. et al. Contribuições para o diálogo intersetorial: a construção do diagnóstico brasileiro sobre biodiversidade e serviços ecossistêmicos. Campinas: Plataforma Brasileira de Biodiversidade e Serviços Ecossistêmicos, 2017. Disponível em: https://www.bpbes.net.br/wp-content/uploads/2018/08/Dialog os_BPBES.pdf

KERSTEN, R.A.; GALVÃO, F. Aspectos da paisagem do município. In: Aves de Curitiba: coletânea de registros. 2.ed. Curitiba: Hori Consultoria Ambiental, 2014. p.31-89.

LANGEMEYER, J. et al. Contrasting values of cultural ecosystem services in urban areas: The case of park Montjuïc in Barcelona. Ecosystem Services, v.12, p.178-186, 2015.

LEAL, L. et al. Influência das florestas urbanas na variação termohigrométrica da área intraurbana de Curitiba - PR. Ciência Florestal, v.24, n.4, p.807-820, 2014.

LEUNG, D.Y.C. et al. Effects of urban vegetation on urban air quality. Landscape Research, v.36, n.2, p.173-188, 2011.

MEA - Millennium Ecosystem Assessment. Ecosystems and human well-being. Washington: Island Press, 2005. Disponível em: http://www.millenniumassessment.org/documents/docum ent.356.aspx.pdf

MEXIA, T. et al. Ecosystem services: urban parks under a magnifying glass. Environmental Research, v.160, p.469-478, 2018.

NAHLIK, A.M. et al. Where is the consensus? A proposed foundation for moving ecosystem service concepts into practice. Ecological Economics, v.77, p.27-35, 2012.

NOWAK, D.J. et al. Carbon storage and sequestration by trees in urban and community areas of the United States. Environmental Pollution, v.178, n.1, p.229-236, 2013.

ONU - United Nations. World urbanization prospects: the 2014 revision. New York: United Nations, 2014. Disponível em: https://esa.un.org/unpd/wup/publications/files/wup2014-high lights.pdf

PARANÁ. População total, urbana e rural dos municípios da Região Metropolitana de Curitiba - 2010. 2012. Disponível em: http://www.comec.pr.gov.br/arquivos/File/RMC/Populacao_Tot al_Urbana_Rural_2012.pdf

PONS, M. et al. Adaptations of the corporate ecosystem services review to a territorial approach. European Institute for Energy Research, 2016. Disponível em: http://serveur.msh-vdl.fr/wpcontent/uploads/2016/06/Pons_et_al..pdf

ROCKSTRÖM, J. Bounding the planetary future: why we need a great transition. Great Transition Initiative, 2015. Disponível em: https://www.greattransition.org/publication/bounding-the-pla netary-future-why-we-need-a-great-transition

RUSSELL, R. et al. Humans and nature: how knowing and experiencing nature affect well-being. Annual Review of Environment and Resources, v.38, p.473-502, 2013.

SIEBER, J. et al. Assessment of ecosystem services for urban resilience - case study in singapore. GRF Davos Planet@Risk, v.3, n.1, p.77-86, 2015.

SOCIEDADE CHAUÁ; PROFLOR CONSULTORIA AMBIENTAL. Plano de manejo da Reserva Particular do Patrimônio Natural Municipal Airumã - Curitiba, PR. Curitiba, 2013.

SPVS - Sociedade de Pesquisa em Vida Selvagem. Bio Boletim Natureza em Curitiba / 2017. Disponível em: http://www.spvs.org.br/wp-content/uploads/downloads/2017/ 03/Bio_Boletim_Curitiba_2017_online.pdf

TAMEKO, A.M. et al. The economic valuation of improved urban parks: a case study of Warda Park. Journal of Sustainable Development, v.4, n.1, p.271-280, 2011.

TEEB - A Economia dos Ecossistemas e da Biodiversidade. Um guia rápido: TEEB para formuladores de políticas locais e regionais, 2010. Disponível em: http://www.teebweb.org/media /2010/09/TEEB-D2-Local-and-Regional-Quick-guide_Portuguese .pdf

UN-HABITAT - United Nations Human Settlements Programme. For a better urban future, 2018. Disponível em: http://urbandata.unhabitat.org/data-country/?countries=BR\& indicators=total_length_road,urban_population_countries,urba n_slum_population_countries,rural_population,population,inco me_gini_coefficient_countries

WARNER, K.E.; LUCE, B.R. Cost-benefit and cost-effectiveness 
BIOFIX Scientific Journal v. 4 n. 1 p. 70-80 2019

Panasolo, A. et al.

analysis in health care. Ann Arbor: Health Administration Press,

1982.

YIN, R.K. Estudo de caso: planejamento e método. 4.ed. Porto Alegre: Bookman, 2010. 